\title{
REFLEXIONES SOBRE LA CLASE DE PALABRA PRONOMBRE
}

\author{
M. ${ }^{a}$ Victorina Crego Garcia \\ Universidad de Santiago de Compostela. Campus de Lugo \\ vicrego@correo.lugo.usc.es
}

\begin{abstract}
Resumen
A review of several works that analyse and classify the different pronoun types brings up two opposied viewpoints: Either the constitution of the pronoun as a grammatical class due to its mutable characteristics or to the desintegration of the pronominal class.

In this article we do not attempt a detailed biographical revision. Therefore, we will not be concerned with a "state of the matter". Instead, we will present the two main conceptual and classifying options to subsequently state our position with regard to the question. We will use a series of parameters or linguistic criteria to justify our position. Although most of the criteria used are of a formal nature, eventually they will be supported by other criteria of a notional or accentual profile.
\end{abstract}

\section{Estado de la cuestión}

La consulta de diferentes obras, esencialmente gramáticas, artículos y monografías, que analizan y clasifican los distintos tipos de pronombres asoma al lector básicamente a dos puntos de vista: al afianzamiento del pronombre como clase gramatical sólida en virtud de rasgos formales variables, aunque de un comportamiento semántico global compartido por otras clases de palabras, o, por el contrario, a la desintegración de la clase pronominal dominante hasta no hace mucho en los estudios gramaticales. No les falta razón a Marcos Marín et alii (1998: 143) cuando nos aclaran que:

\footnotetext{
El pronombre, como categoría gramatical, ha sido cuestionado por muchos gramáticos que han reaccionado contra la idea que del pronombre tenía la gramática tradicional, como "aquella clase de palabra que sustituye al nombre para evitar su repetición". Las críticas que se han hecho al pronombre han alcanzado tal grado que se ha llegado a querer eliminar el término pronombre, por inadecuado, y emplear en su lugar otros, como proformas, sustitutos o simplemente pros. Ya R. Lenz (1935) proponía hablar de pronombres sustantivos, pronombres adjetivos, proverbos y proadverbios. Por respeto a la tradición gramatical, se sigue empleando el término pronombre, pero es conveniente definir claramente este tipo de palabras para evitar equívocos e incorrecciones.
}

\footnotetext{
1 En este apartado inicial no pretendemos llevar a cabo un repaso histórico del pronombre en la Gramática española ni un análisis bibliográfico pormenorizado de este, sino ofrecer una visión panorámica de la complejidad conceptual que implica esta clase de palabra desde su propia definición hasta su aplicación en secuencias concretas.
} 
Este fragmento expone de forma clara la problemática que entraña la caracterización de la clase de palabra pronombre en la Gramática española. En líneas generales, se considera el pronombre como un sustituto de nombre, sin aclarar qué entendemos por sustituto y a qué nos referimos con la etiqueta nombre. Realmente si le otorgamos a esta clase de palabra la propiedad de la sustitución estamos realizando una definición por negación basada en un principio paradigmático, esto es, en las relaciones paradigmáticas "in absentia" consolidadas por lingüistas como Saussure (1916) y Hjelmslev (1928) ${ }^{2}$.

Esto supone obviar los principios gramaticales (o formales, si lo preferimos) que se deben instrumentalizar para caracterizar las clases de palabras. Así, el sustantivo se individualiza mediante la presencia de género y número inherentes y de un determinante antecediéndolo y un modificador siguiéndolo (o en posición prenuclear); el determinante por su posición prenuclear; el adverbio por modificar al verbo, al adjetivo o a otro adverbio y por ser invariable; y así, sucesivamente.

Además de fundamentar la caracterización del pronombre en un principio por negación, surge la duda, ya mencionada, de qué entendemos por nombre. En principio, esta etiqueta parece englobar a sustantivos y adjetivos, pero como podremos comprobar en última instancia incluirá frases (sustantivas, nominales o preposicionales) y oraciones ${ }^{3}$ (v.gr., Quiero a tu padre / dinero / que vengas a mi casa $\rightarrow$ Quiero eso, Lo quiero).

Asimismo, se pone el acento en la naturaleza semántica del pronombre, habida cuenta de que no remite a un significado léxico o simbólico sino a un contenido de naturaleza ocasional o contextual, esto es, variable en función de las circunstancias discursivas, fenómeno denominado deixis. No obstante, no debemos olvidar que la deixis también aparece en clases de palabras como el sustantivo, el determinante, el adverbio o el verbo, además de que se trata de un criterio de perfil nocional que no responde a las expectativas de una definición formal.

Tampoco conviene soslayar que en el interior del pronombre conviven, tal y como lo reflejan las gramáticas del español, diferentes subtipos que en más de una ocasión constatan la existencia de más diferencias entre sí que concomitancias. Refresquemos la memoria: personales, demostrativos, posesivos, indefinidos o cuantificadores, relativos, interrogativos y exclamativos.

\section{Caracterización del pronombre desde distintos prismas lingüísticos}

Todo este mosaico de rasgos lingüísticos ha convertido el pronombre en una especie de cajón de sastre en el que tienen cabida unidades lingüísticas de distinta naturaleza, tal y como han sido definidas. En nuestro caso, procuraremos basar la existencia de una categoría gramatical en fundamentos morfológicos, sintáctico-distribucionales, semánticos y, en último término, acentuales. No obstante, queremos ya hacer hincapié en que los criterios que adquirirán prioridad en este trabajo son los dos primeros, dada su naturaleza formal. Los

3 Este comportamiento enfatiza la inexistencia de relación biunívoca entre una clase de unidad o categoria determinada y la función sintáctica que esta desempeña, pauta sintáctica defendida por funcionalistas como Rojo (1983: 55-56) y Rojo y Jiménez Juliá (1989: 96-97).

4 Cfr. Alcina y Blecua (1975), R.A.E. (1973) y Seco (1989). 
dos últimos se instrumentalizarán de forma subsidiaria, aun cuando en algunas ocasiones aparezcan vinculados a factores estructurales de perfil sintáctico-semántico.

También queremos aclarar que mantendremos la etiqueta pronombre debido a la fuerza innegable de la tradición gramatical. Esta conservación no significa que defendamos el trasfondo de tal término ('sustituto de...') como tampoco significó en su momento el uso del término sustantivo la asociación, al menos en todos los casos, al contenido que inicialmente se le atribuía a este ('sustancia').

En esta decisión terminológica, pero sobre todo conceptual, resultan clarificadoras las consideraciones de González Calvo (1998: 258) con respecto a la decisión de incluir determinadas unidades en el cajón del morfema o de la palabra, consideraciones que asumimos como válidas e iluminadoras en relación con nuestra decisión de seguir preservando el pronombre como entidad lingüística independiente:

Como las fronteras entre el morfema y la palabra no son siempre claras (sucede en todas las zonas del lenguaje, lo que es signo o indicio de su vitalidad), los casos fronterizos plantean obstáculos y controversias. No es tan grave el asunto y se entiende perfectamente. Por ejemplo, el llamado artículo determinado en español tiene características morfemáticas (atonicidad, falta de autonomía oracional, significado no léxico) y características no morfemáticas (límites formales libres que permiten insertar elementos entre artículo y sustantivo, moción de género y número, combinatorias diferentes a las puramente morfemáticas). No es de extrañar, pues, que unos autores le den el empujoncito hacia el morfema y otros [...] se lo den hacia la palabra [...]; a la postre, en lo fundamental, las teorías no son tan dispares, sí las matizaciones y precisiones. Que el artículo, las preposiciones y las conjunciones se consideren morfemas y no palabras, lo único que muestra es que se engorda el cajón del morfema y se alivia o adelgaza el de la palabra en ese terreno inestable de la frontera [...]. Siempre el confusionismo conceptual acarrea embrollo terminológico.

\subsection{Caracterización morfológica o formal}

Si partimos de la presencia de los considerados accidentes gramaticales en el seno del pronombre, nos encontramos con un comportamiento variopinto. Así, un conjunto no desdeñable de pronombres ofrece variación genérica y numérica ${ }^{5}$ (los personales yo-nosotros (as), tú-vosotros(as); los posesivos suyo-a, suyos-as; los demostrativos este-esta-esto, estos-estas); otros, no obstante, varían exclusivamente en el nivel genérico (este es el caso de los cuantificadores vario(a)s y ninguno(a)); algunos, en contrapartida, muestran sólo flexión numérica (el relativo quien(s); el cuantificador bastante(s)); otros son invariables (los cuantificadores imprecisos nada, nadie, algo, cualquiera, más, menos; el relativo que; los exclamativos e interrogativos qué y cómo); un pequeño porcentaje de pronombres remite a una triple variación genérica (los personales: él-ella-ello/lo; los demostrativos: este-estaesto); un no tan pequeño porcentaje no materializa la alternativa genérica neutro (el resto de los no mencionados); en tanto que pocos pronombres actualizan una reliquia de raigambre latina: la presencia de variación casual (yo / me / mí / conmigo; tú / te / ti / contigo; él / lo, la, los, las, lo / le, les / consigo). 
Este comportamiento heteróclito significa, ni más ni menos, que no existe una sola categoría gramatical compartida por todos los pronombres distinguidos por la tradición gramatical.

Hay que resaltar que la presencia de accidentes gramaticales como género neutro, persona y caso nunca se han asociado a los sustantivos. Sin embargo, investigadores como Alarcos Llorach (1994) y González Calvo (1998) introducen los pronombres que incluyen tal posibilidad en el ámbito de los sustantivos (vid. infra 2.3.) $)^{6}$. Otros, como Leonetti (1999: 29), los consideran determinantes:

\begin{abstract}
¿Por qué los pronombres funcionan como SSNN, si no son nombres y tienen una semántica muy distinta de la de los nombres? La tradición gramatical nos ha acostumbrado a pensar que los pronombres sustituyen a los nombres y que el comportamiento de SN de los pronombres es un reflejo de esta relación. Sin embargo, hoy sabemos que la idea de la sustitución no nos lleva muy lejos, y por otra parte no permite entender la semántica de los pronombres. Sin duda es más razonable pensar que, si los determinantes son [...] los responsables del comportamiento gramatical de los SSNN, y los pronombres funcionan de manera similar a los SSNN, es el hecho de ser determinantes lo que explica la gramática de los pronombres. En realidad esa es la única forma de acercarse a una comprensión cabal de su significado, ya que, por un lado, es evidente que están desprovistos de contenido conceptual (lo que los separa de los nombres), y por otro parece claro que su contenido está al servicio de las operaciones de referencia y de cuantificación (como el de los determinantes).
\end{abstract}

\title{
2.2. Caracterización paradigmática
}

Desde este punto de vista se defiende, tal y como se ha subrayado con anterioridad, que el pronombre funciona como un sustituto del nombre, a lo que se puede responder con una serie de contraejemplos como los siguientes:

(1) Ayer yo no fui al cine $\rightarrow$ * Ayer Vicky no fui al cine

(2) Ayer tú no fuiste al cine $\rightarrow$ * Ayer Montse no fuiste al cine

(3) Vosotros, los alumnos, tenéis una serie de responsabilidades

(4) Le he devuelto a Maria el libro que me prestó

(5) He devuelto el libro que me regalaste $\rightarrow{ }^{*}$ He devuelto el libro el libro me regalaste

Los pronombres personales yo y tü no sustituyen a ningún nombre, antes bien se refieren a las personas o entes personificados (emisor y receptor) que participan en un acto comunicativo y que varían dependiendo del ser que tome el turno de habla o de la palabra. Esta naturaleza impide que conmutemos ambos pronombres por nombres propios o frases nominales ${ }^{7}$ (supra (1) y (2)). Por otra parte, en las secuencias en las que se materializa el fe-

6 Cfr. Alarcos Llorach (1970a y 1970b).

7 En el ámbito de los denominados pronombres personales es conveniente destacar dos hechos lingüísticos: por una parte, la presencia del pronombre de tercera persona neutro, ello, que hoy en día se emplea básicamente en el registro escrito, lo que posiblemente significa que en no mucho tiempo se convertirá en un uso obsoleto; por otra parte, las formas conmigo, contigo y consigo son el resultado de la fusión de la cadena: preposición + pronombre + preposición: cum + me /te/se + cum (cummecum, cumtecum, cumsecum). Esta evolución histórica ha desarrollado estas variantes pronominales que sustituyen a una frase preposicional encabezada por la preposición con: No pienso ir con Luisa $\rightarrow$ No pienso ir contigo. 
nómeno del "uso redundante del pronombre" asociado a mecanismos informativos o estrictamente construccionales, no es viable defender la sustitución cuando la estructura a la que, en teoría, reemplaza está presente en idéntica estructura en una relación clara de contraste sintagmático (supra (4) $)^{8}$. Asimismo, en la secuencia (3) el mecanismo de la aposición da lugar a la copresencia del pronombre y del segmento léxico al que "teóricamente" sustituye. Y, por último, en el área de los denominados pronombres relativos en ningún caso podremos defender el proceso de sustitución sin que aparezca una estructura incorrecta ${ }^{9}$ (supra (5)).

No obstante, también se ha de admitir que los pronombres funcionan como sustitutos en secuencias de la naturaleza de:

(6) Este [niño] es irresponsable

(7) ¿Qué quieres de mí? [Que estudies],

comportamiento lingüístico que subraya, una vez más, que tampoco existe una definición paradigmática exclusiva para la totalidad de los pronombres ${ }^{10}$.

Además, existen otras clases de palabras que funcionan como sustitutos:

(a) El proverbo hacer: Pedro tomó el café y Juan hizo lo mismo.

(b) El adverbio modal asi: Me siento enferma $\rightarrow$ Me siento asi.

(c) Los adverbios locativos aquí, ahi, allí: Ayer estuvo en tu casa $\rightarrow$ Ayer estuvo aquí/ ahí/allí.

(d) Los adverbios temporales ahora y entonces: En este momento voy a tu casa $\rightarrow$ Ahora / entonces voy a tu casa.

(e) El adverbio afirmativo también: Juan ha ido al cine y yo también.

(f) Sustantivos como cosa, rollo, chisme, cuestión, dimensión, aspecto, prisma o punto (de vista): Esa película trata de la Segunda Guerra Mundial pero esta no trata ese aspecto/rollo.

\subsection{Caracterización distribucional}

Este prisma responde a un rasgo compartido por gran parte de la tipología pronominal: la ausencia de actualizadores antecediéndolos y de modificadores siguiéndolos o antecediéndolos. Con respecto a la ausencia de actualizadores hay que constatar que:

\footnotetext{
Asimismo, queremos constatar que las formas de tratamiento cortés o de respeto, usted y ustedes, frente a las de familiaridad, tú-vosotros, son utilizadas en España parcialmente, dado que en el occidente de Andalucía y en las Islas Canarias se neutraliza la oposición vosotros / ustedes a favor de este último pronombre. Esto también sucede en la totalidad de los paises de Hispanoamérica (cfr. Fontanella de Weinberg, 1999).

8 Vid. Garcia-Miguel (1991), García-Miguel y Vázquez Rozas (1994), Jaeggli (1993) y Suñer (1999).

9 Si nos ceñimos a una caracterización coherente del pronombre deberemos excluir de la clase relativa el determinante nexual cuyo, habida cuenta de que se trata de un componente lingüístico que ha de incluirse en el ámbito de aquellos que preceden al sustantivo al que actualizan. La diferencia que culyo presenta frente al resto de la clase de determinantes se cifra en que siempre une dos oraciones: la oración principal y la subordinada relativa en la que este elemento sigue al antecedente al que se refiere (deixis anafórica) y en la que el sustantivo al que actualiza representa el objeto poseído con el que concuerda necesariamente en género y número (Las familias cuyos hijos tengan problemas deben presentarse en estas dependencias).
}

10 Sobre los interrogativos véase López Palma (1999: 199-274). 
(a) La clase de los posesivos cuando no funciona como atributo o predicativo (o como modificador en el nivel frasal) va precedida siempre de artículo: El tuyo no tiene arreglo / Este libro es (el) tuyo, Este hijo tuyo es un inocente, No quiero ver al tuyo [hijo] (cfr. Picallo y Rigau, 1999).

(b) Algunos indefinidos como otro, mismo y demás, los ordinales (El primer, El segundo...) y los múltiplos ( $\boldsymbol{E l}$ doble, $\boldsymbol{E l}$ triple...) muestran, o bien idéntica necesidad ( $\mathrm{l}$ mismo y los demás) o ambas alternativas estructurales (otro, el otro): El primer día voy yo a clase, mientras que el segundo asistes tú; Mientras que este me contestaba (los) otros no me atendian (cfr. Marcos Marín, 1999).

(c) Relativos tónicos como el cual, la cual, lo cual y átonos como el que, la que, lo que siguen el mismo criterio: La persona de la cual dependo no eres tú, La mujer a la que viste no vive aquí.

(d) Asimismo, a esta caracterización distribucional se le puede objetar la presencia de modificadores como mismo o el numeral cardinal seis (con distribución postnuclear) o todo (con distribución prenuclear): Yo mismo lo hice, Nosotros seis no le hicimos caso, Toda ella es falsa.

Pese a la existencia de esta serie de observaciones, será este el criterio formal que nos permitirá reunir bajo la misma clase gramatical la amplia totalidad de los pronombres (bien es cierto que con alguna exclusión inevitable), esto es, el hecho de que incluyan el rasgo 'actualización' que impide en gran parte de la clase pronominal la presencia de los determinantes que ejecutan esa función.

La naturaleza no generalizada de este opción construccional no obsta para que, en ocasiones, seamos capaces de aportar una explicación a la aparición del artículo mientras que en otras recurriremos al principio de prototipicidad que, al menos, nos permitirá, según nuestro juicio, seguir englobando en la misma clase gramatical los diferentes subtipos de pronombres ${ }^{11}$. En caso de que busquemos categorías absolutas, en ningún momento podremos continuar manteniendo la clase de palabra pronombre, sino que habrá que apostar por alternativas como las de Alarcos Llorach (1994) y González Calvo (1998). De hecho, si nos hacemos eco de las palabras que el primero utiliza para caracterizar los denominados tradicionalmente pronombres personales:

Para designar estas unidades personales, es poco adecuado el término de pronombre. No puede aceptarse la idea de que sean siempre "sustitutos" del nombre o sustantivo, aunque ciertamente desempeñan en el enunciado papeles semejantes. Los llamados pronombres personales tónicos constituyen en realidad una subclase de los sustantivos, puesto que coinciden con estos en su función, y, al menos parcialmente, entrañan unos mismos tipos de accidentes o morfemas (el número y el género). Los llamaremos, pues, sustantivos personales.

11 Las caracterizaciones absolutas no funcionan en ninguna de las clases de palabras del español. Si nos centramos, para ilustrar esta afimación, en la clase sustantivo podremos comprobar: la heterogeneidad formal, en tanto en cuanto no varían todos en género y número (mesa, arras, norte), o no varían como norma habitual en número (sustantivos propios como Juan y Pedro), la heterogeneidad funcional (pueden desempeñar cualquier función primaria, además de la secundaria modificador) y, cómo no, la heterogeneidad semántica (que da sentido a las antinomias: sustantivos concretos / abstractos, comunes / propios, individuales / colectivos, continuos / discontinuos). 
En ellos se combinan un contenido léxico y unos significados gramaticales, como los sustantivos en general. Pero frente a estos, la especificidad de los personales consiste en que la referencia léxica se restringe a la mera mención de la persona (componente este que en otro tipo de palabras funciona como un morfema, según ocurre en el verbo [...]. Se distinguen, pues, personales de primera persona, de segunda y de tercera (Alarcos Llorach, 1994: 71).

Por otra parte, en este apartado que nos acerca al plano de la distribución secuencial, así como al nivel estrictamente funcional, hay que realizar una distinción que opone pronombres nexuales (los relativos integrados en oraciones relativas especificativas o nominalizadas y los interrogativos incrustados en oraciones interrogativas indirectas) de los no nexuales (el resto de la tipología pronominal):

(8) Quien bien te quiere, te hará llorar (función del relativo: sujeto)

(9) No entiendo lo que pretendes (función del relativo: complemento directo)

(10) No vi al niño que te golpeó (función del relativo: sujeto)

(11) No entiendo qué pretendes (función del interrogativo: complemento directo)

(12) Dime cuál prefieres (función del interrogativo: complemento directo)

Como se podrá deducir, los pronombres nexuales son aquellos que, además de realizar una función sintáctica en la estructura subordinada en la que aparecen, funcionan como nexo entre dos oraciones. Se trata de pronombres que se comportan como elementos "puente" y que se hallan ubicados entre las clases de palabras léxicas (gran parte de los sustantivos, de los verbos y un porcentaje no desdeñable de adverbios, además de los adjetivos) y las clases de palabras gramaticales (grosso modo, preposiciones y conjunciones).

\subsection{Caracterización sintáctica}

Los pronombres no están especializados en ninguna función sintáctica en particular. Pueden desempeñar cualquier función sintáctica:
(13) Yo no quiero ni verte (sujeto)
(14) No los vio a ellos sino a nosotras (complemento directo)
(15) No le pienso contar a cualquiera mis problemas (complemento indirecto)
(16) Dependo de este [marido] desde 1980 (suplemento)
(17) Este libro es el suyo (atributo o predicativo)
(18) Fue maltratada por todos [los soldados] (complemento agente)
(19) Entre tú y yo hay un problema muy serio (complemento circunstancial)

Pese a esta más que evidente libertad funcional del pronombre, la teoría gramatical suele etiquetarla como sustantivación de los pronombres (en otros casos existirá adjetivación o adverbialización), lo que abrirá el camino a aquellos investigadores que consideren oportuno integrar el pronombre en el ámbito de otras clases de palabras (cfr. supra 2.3.). Sin embargo, si asumimos que esta transposición o, si se prefiere, recategorización no implica realmente que el pronombre se haya convertido en otro subtipo de palabra, teniendo en cuenta, por supuesto, los parámetros con los que inicialmente se lo caracteri- 
$\mathrm{za}^{12}$ (formal, funcional y nocional, básicamente), podremos optar por otras vías analíticas cuando menos aceptables. Representan una de estas vías Rojo y Jiménez Juliá (1989: 96-97), quienes opinan que:

[...] pertenecen a la misma clase paradigmática todas las cadenas que contraen relaciones paradigmáticas, es decir, todas las cadenas que pueden aparecer en el mismo hueco funcional. En consecuencia, viejo, de aventuras y que me regalaron pertenecen a la misma clase paradigmática, ya que todos ellos pueden desempeñar la función de modificador de una frase nominal:

[...] El libro viejo

[...] El libro de aventuras

[...] El libro que me regalaron

Sin embargo, viejo es una palabra (en concreto, un adjetivo), de aventuras es una frase preposicional y que me regalaron es una cláusula, de modo que está claro que no pertenecen al mismo tipo de unidad. Lo que decide la pertenencia a una clase paradigmática es la capacidad para desempeñar una determinada función (como se ve, [...] [aparece] la referencia a algo exterior al elemento mismo). El factor pertinente para la adscripción a un cierto tipo o subtipo de unidad pasa por la existencia de determinadas características internas al propio elemento.

Es claro, además, que la pertenencia a distintos subtipos del mismo tipo supone habitualmente la vinculación a clases paradigmáticas diferentes (lo cual se explica por el hecho de que los subtipos se establecen por las diferencias en las capacidades funcionales de las cadenas). Así, por ejemplo, libro y alegre son dos clases de palabras que pertenecen a distintos subtipos (sustantivo y adjetivo, respectivamente) y a clases paradigmáticas diferentes: alegre pertenece a la misma clase paradigmática de viejo, aventuras y que me regalaron, esto es, la constituida por los elementos que pueden funcionar como modificadores en el interior de una frase nominal, mientras que libro, como niña, casa, etc. debe ser incluido en la clase paradigmática de los elementos que pueden funcionar como núcleos de una frase sustantiva.

\subsection{Caracterización semántica}

Los pronombres comparten el mecanismo de la deixis mediante la anáfora o la catáfora, en virtud de que, respectivamente, hagan referencia a algo mencionado anteriormente en el discurso escrito (referencia o deixis endofórica) u oral (deixis exofórica) o a algo mencionado con posterioridad en el registro oral o escrito (cfr. Carbonero Cano, 1979; Eguren, 1999):

12 Unidades lingüísticas que, sin ningún lugar a dudas, han sufrido el proceso de recategorización son: sustantivos como menoscabo, menosprecio, nada, naderia, mismidad, demasia, (un don) nadie y (una(s)) cualquiera(s), procedentes de indefinidos; sustantivos de la naturaleza de (mi(s)) yo(es), que tienen su origen en un pronombre personal; sustantivos de la tipología de (el) porqué, que originariamente era sólo un interrogativo; verbos como ningunear, que proceden de indefinidos. Asimismo, un porcentaje elevado de indefinidos pueden dar lugar a pronombres, determinantes o adverbios (v.gr. Lei muchos libros $\rightarrow$ Lei mucho; Lei muchas novelas; Te quiero mucho). Serán los parámetros formales los que nos darán la pauta lingüística que nos permita integrar estas unidades en un tipo u otro. 
(20) -Este cuadro me gusta más que ese -Pues yo prefiero este a ese (anáfora exofórica)

(21) ¿Me pasas ese lápiz que está encima de la mesa? (anáfora endofórica)

(22) Eso de que hablas no me interesa (catáfora endofórica)

(23) Escucha esto que voy a decirte porque es interesante (catáfora endofórica)

Es conveniente incidir, una vez más, en que el punto de vista semántico representa un componente informativo importante en el momento de describir una unidad lingüística pero que constituye un factor $\mathrm{y} / \mathrm{o}$ criterio subsidiario dado que no desemboca en distinciones formales pertinentes. De hecho, el rasgo deixis es poseído por diferentes clases de palabras: pronombre, verbo, adverbio, sustantivo y determinante. En consecuencia, no resulta opositivo en el sistema de las clases de palabras del español.

\subsection{Caracterización acentual}

La mayor parte de los pronombres son tónicos, rasgo fónico que aparece asociado a una dimensión sintáctico-semántica, esto es, a la autonomía lingüística de la que carecen los considerados tradicionalmente pronombres personales átonos y gran parte de los relativos.

El carácter tónico de una unidad es el que determina que posea tal autonomía y que, en consecuencia, según la opinión de algunos investigadores, se incluya en el ámbito de la palabra ${ }^{13}$

13 A pesar de que a priori la palabra es una unidad con la que el hablante de una lengua se siente familiarizado, en el momento de llevar a cabo su delimitación y definición hallamos diferentes escollos. Dependiendo del criterio utilizado, se integrará un tipo de unidad u otro en el concepto palabra, de manera que los resultados emanados de cada criterio son claramente divergentes.

Si recurrimos al criterio ortográfico o de la separabilidad, según el cual las palabras se encuentran situadas entre blancos de escritura, deberemos admitir que los clíticos pronominales son palabras en algunas ocasiones (Me lo dio ayer) y en otras no (Dámelo inmediatamente), frente a la pertenencia indiscutible de sustantivos, adjetivos, determinantes, preposiciones o conjunciones a esta concepción de la palabra. No obstante, utilizando este criterio, aprisa, asimismo y enseguida serían una palabra y de prisa, asi mismo y en seguida dos, en tanto que unidades como piso-piloto y piso piloto indican la gradación en la fusión de dos lexemas en el marco de la misma unidad léxica, dado que el guión es el índice ortográfico de la incertidumbre con respecto a la personalidad de la palabra.

Por otra parte, si es el criterio de la autonomía semántica el que se utiliza, podremos constatar que son palabras componentes léxicos como los adjetivos calificativos, los sustantivos, los adverbios y los verbos, elementos autosemánticos o significativos por sí mismos, pero no elementos como las preposiciones, las conjunciones, los pronombres y los determinantes, unidades que, sin embargo, constituyen palabras si optamos por el criterio ortográfico o de la separabilidad.

En tercer lugar, si seleccionamos el criterio funcional, que se fundamenta en la posibilidad de las palabras de desempeñar funciones sintácticas oracionales, nos topamos con que los adjetivos, adverbios y sustantivos, así como los pronombres clíticos (proclíticos o enclíticos a la entidad verbal), desempeñan funciones sintácticas propias de la oración (funciones primarias), mientras que no gozan de esa posibilidad unidades lingüísticas como los determinantes, las conjunciones o las preposiciones (los primeros desempeñan una función secundaria en el seno de la frase nominal). Si complementamos este criterio con la capacidad de las palabras de constituir enunciado, esto es, de poseer autonomia oracional, deberiamos excluir de la unidad palabra los pronombres clíticos ya que necesitan del verbo para conformar un enunciado. De hecho, Bloomfield opina que la palabra es una "forma libre mínima", definición que adquiere sentido en el interior de la distinción previa realizada por este investigador entre formas libres y formas ligadas. Las formas que nunca aparecen solas como expresiones completas (en alguna situación discursiva normal) son formas ligadas y las formas que pueden aparecer solas como expresiones son formas libres. Asumiendo de forma coherente esta óptica, integraríamos en los morfemas libres: los clíticos pronominales proclíticos, el artículo, los determinantes posesivos, las preposiciones y las conjunciones; en los morfemas ligados se incluirían: los clíticos pronominales enclíticos y categorías gramaticales como el género, el número, el caso o la persona. 
o clase de palabra (cfr. González Calvo, 1982). En contrapartida, la carencia de acento de entonación nos conduce a elementos morfológicos semejantes a los morfemas, con la diferencia de que se trata de morfemas libres (los pronombres personales átonos en posición proclítica: Se lo dices cuando lo veas) o ligados (los mismos pronombres en distribución enclítica: Díselo cuando lo veas) $)^{14}$. Este punto de vista ha sido defendido en su momento por investigadores como Bloomfield (1933) y Alarcos Llorach (1994), al tiempo que otros, haciendo gala de una contundencia en la "reclasificación" de las clases de palabras, han incluido los pronombres personales átonos en la conjugación objetiva en virtud de la variación de clíticos verbales (cfr. Heger, 1966; Llorente y Mondéjar, 1974; García-Miguel, 1995a: 33-34; 1995b: 4415).

Esta dimensión acentual permite, creemos que indudablemente, la segregación de tales unidades de la clase pronominal y su inclusión en la tipología morfémica. Esta decisión, o visión, no está reñida con el comportamiento o las posibilidades estructurales del español, en tanto en cuanto detectamos morfemas libres o ligados que, al mismo tiempo, desempeñan o marcan una función sintáctica determinada. Esta alternativa, de hecho, la encontramos en el latín en el ámbito de los casos: "sufijos" que nos indican qué función sintáctica desempeña la palabra en la que se integran. La dicotomía proclítico / enclítico está vinculada a un nivel meramente sustancial, no formal.

Por otra parte, si tenemos en cuenta los pronombres relativos podremos verificar que son todos átonos excepto el cual (y variantes). Este comportamiento nos sitúa en una postura en principio, y aparentemente, menos resolutiva que la anterior habida cuenta de que encontramos un contraejemplo a la premisa que queremos elevar al nivel de principio estructural. No obstante, ciñéndonos al comportamiento prototípico y, por ende, más extendido, es plausible negar su naturaleza pronominal prototípica, añadiendo, además, que no es aventurado explicar la presencia del artículo para diferenciar el cual relativo (recordemos que es tónico) del cuál interrogativo, también de naturaleza tónica (La persona de la cual dependo es mi marido, Dime cuál es tu problema) y de la conjunción comparativo-modal cual (El perro corría cual gacela). De la misma manera, la forma el que (y variantes) integraría el artículo con semejante finalidad: diferenciar el que relativo de la conjunción completiva que (No le digas lo que piensas, No le digas que piensas eso de ella).

\footnotetext{
14 Cfr. Fernández Soriano (1993: 22-23, 39-45).

15 Según García-Miguel (1995: 44): "el criterio que [...] resulta más significativo en la decisión de considerar SUJ[eto], CDIR[complemento directo] y CIND[complemento indirecto] como funciones centrales de las cláusulas del español es la posibilidad de integración en el predicado[entidad verbal] mediante afijos o mediante clíticos pronominales. Los clíticos le y lo forman parte fonológicamente del predicado y, funcionalmente, dejan libre (lo mismo que las desinencias de número y persona concordantes con el sujeto) las posiciones sintácticas de CDIR o CIND para ser ocupadas por un constituyente 'pleno' (tónico). En los ejemplos que siguen, la estructura de constituyentes es [...] la que se indica mediante corchetes rotulados funcionalmente:
}

$$
\begin{aligned}
& \text { a. }[\text { Juan }]_{\text {SUS }} \\
& \text { b. }[\text { A Pedro }]_{\text {CDIR }} \\
& \text { c. }[\text { Juan }]_{\text {SUJ }}
\end{aligned}
$$

$[\text { lo vio }]_{\text {PRED }}$

[lo vio $]_{\text {PREI }}$

[le compró $]_{\text {PRED }}$ [a él] $]_{\text {CDIR }}$ [Juan] [un libro $]_{\text {COR }}$ [a Pedro $]_{\text {CIND }} "$ 


\section{Caracterización y clasificación del pronombre}

Investigadores como Alarcos Llorach (1994) y González Calvo (1998) incluyen los pronombres en el ámbito de los sustantivos en función de que comparten combinatoria y, por tanto, semejante comportamiento sintáctico. La diferencia, en opinión de ambos lingüistas, reside en el plano nocional, con respecto al que distinguen sustantivos léxicos (con significado simbólico) de sustantivos pronominales (con significado contextual, ocasional o referencial). Es en esta última subclase en la que incorporan los tradicionales pronombres personales, demostrativos, posesivos, cuantificadores, interrogativos y exclamativos.

No obstante, en nuestra opinión, se puede mantener el pronombre como clase independiente de palabra partiendo de propiedades de naturaleza formal, no semántica.

Desde el punto de vista morfológico algunos pronombres varían en género y/o número concordantes (no inherentes, frente a la naturaleza inherente del género y del número en el ámbito del sustantivo), además de que se pueden distinguir accidentes como el género neutro (pronombres personales, demostrativos, posesivos y algunos cuantificadores), la persona (pronombres personales y posesivos) y el caso (pronombres personales), accidentes que no tienen cabida en la categoría sustantivo. Por su parte, la morfología derivativa nos permitirá constatar que la clase pronominal no admite la prefijación y en contadas ocasiones tolera la sufijación que indica gradación (muchísimo, tantísimo, poquísimo: Leo muchísimos libros $\rightarrow$ Leo muchísimos) o naturaleza diminutiva (poquito: Leo poquitos libros $\rightarrow$ Leo poquitos $)^{16}$.

Consecuentemente, de este último párrafo podemos extraer la conclusión de que en el paradigma de los pronombres resulta más pertinente o significativa la morfología derivativa que la flexiva, principio que no se puede elevar a un nivel absoluto, debido a que este comportamiento lo podemos rastrear también en clases de palabras como el adverbio.

Si partimos del comportamiento sintáctico-distribucional podremos verificar que gran parte de los pronombres no aparecen precedidos por determinantes ni admiten modificadores antepuestos o postpuestos, siendo este, por tanto, el comportamiento prototípico de esta clase de palabras. Nos encontramos con casos que, aparentemente al menos, permiten una explicación razonable. Nos referimos a los pronombres posesivos, con respecto a los que existe una distribución complementaria indiscutible: cuando el posesivo funciona como atributo o predicativo (función primaria), con verbos como ser o parecer, en el nivel oracional y en los casos en que desempeña la función de modificador en el nivel frasal (función secundaria) es viable la ausencia de artículo, en tanto que en el momento en que desempeña otras funciones oracionales o primarias ha de combinarse necesariamente con el artículo: Este coche es (el) suyo, Este hijo mío es un desastre, El suyo [coche] no me interesa (sujeto), yo no compré el suyo [coche] (complemento directo), No cuento ya con el suyo [dinero] (suplemento) ${ }^{17}$.

16 Estructuras de la naturaleza de Este libro es totalmente mio nos conducen a la gradación pronominal desde un prisma analítico, opción minoritaria en esta clase de palabra; otras, como Luis es muy suyo, deben ser tratadas a modo de recategorizaciones del pronombre posesivo en adjetivo.

17 Con respecto a estructuras con artículo como el mio o el tuyo existen diferentes posturas:

(a) La de aquellos que como Lapesa (1975) y Fernández Ramírez (1987) opinan que en estas construcciones el artículo desempeña la función primaria y el posesivo funciona como un adjetivo. 
En el caso de cuantificadores, entendidos en un sentido amplio, de la naturaleza de mismo, demás, primero o triple es posible que la aparición necesaria del artículo venga dada en los dos primeros pronombres por la indefinición semántica a que aluden y en los dos últimos se puede relacionar con una dimensión de naturaleza evolutiva o diacrónica, por tanto, con una fijación estructural emanada de la rigidez que imprime el paso del tiempo sin que se operen cambios lingüísticos en un parámetro concreto del sistema lingüístico. Recordemos que el sistema lingüístico en general es inherentemente inmutable e mutable, contradicción aparente que adquiere sentido en una lengua viva normalizada y normativizada pero que evoluciona o cambia en virtud del eje diacrónico, además del diatópico, el diastrástico y el diafásico.

Por otra parte, la vertiente acentual nos instala en una clase gramatical prototípicamente tónica y, consecuentemente, en el ámbito de unidades lingüísticas que gozan de autonomía sintáctico-semántica en el discurso en el que se realizan.

La dimensión nocional no muestra comportamientos desviados o desviaciones en el seno de los pronombres, dado que todos ellos poseen un significado no simbólico o contextual que hace referencia (no siempre sustituye) a una unidad de contenido léxico que aparece antes o después en la cadena oral o escrita. El prisma semántico, además de que, en general, no aparece siempre vinculado a estructuras que respalden su pertinencia para diferenciar clases de palabras, en este caso es compartido por otras palabras: determinante, sustantivo, verbo, adverbio. Por tanto, no nos resulta útil en una caracterización de fundamentos formales.

En opinión de González Calvo (1998: 263):

Entre las partes tradicionales de la oración suele incluirse el pronombre. Parece que esta apreciación es errónea, y su exclusión de las mencionadas partes no es de ahora. Sabemos que El Brocense, Andrés Bello, Rodolfo Lenz y Amado Alonso y Pedro Henriquez Ureña, por ejemplo, lo rechazan. Para A. Alonso y P. Henríquez Ureña, el pronombre es una categoría semántica; y es una categoría transversal desde el punto de vista morfosintáctico, ya que esas palabras con un contenido deíctico y esencialmente ocasional son sustantivos, adjetivos, adverbios... María Ángeles Álvarez Martínez [...] llega a la conclusión, que parece correcta, de que el pronombre no es una categoría funcional.

Quizás este perfil deíctico interviene en el carácter cerrado o limitado de las entidades pronominales, carácter paralelo al poseído por los determinantes. De hecho, si exceptuamos los pronombres personales, el resto de los pronombres siempre tiene un correlato, apocopado o no, que funciona como determinante, de manera que actualiza o presenta el segmento lingüístico que lo sigue:

(b) La opinión de investigadores como Porto Dapena (1982: 61-62) que consideran que hay que hablar de un proceso elíptico y que, consecuentemente, se ha de recuperar un sustantivo elidido u omitido, de modo que el posesivo funciona como adjunto.

(c) Y, finalmente, el punto de vista de investigadores como Alonso y Henríquez Ureña (1971: 224), Gili Gaya (1973: 239) y Álvarez (1986: 73-77) que conciben al artículo como transpositor del posesivo a la función sustantiva. En el ámbito de este proceso lingüistico el adjetivo pasa a funcionar como lo haría un sustantivo. 


\section{Pronombres}

Este

Qué

Uno

Cualquiera

(Los) seis

(EI) suyo

\section{Determinantes}

$\rightarrow \quad$ Este [niño] es un impertinente

$\rightarrow \quad$ Qué [tontería] acabas de decir!

$\rightarrow \quad$ Un $(o)$ [niño] llegó tarde

$\rightarrow \quad$ Cualquier(a) [persona] te pudo ver

$\rightarrow \quad$ [Los] seis [niños] llegaron tarde

$\rightarrow \quad$ (El) $\mathrm{Su}($ yo) [hijo] no se porta bien

Asimismo, algunas de las formas pronominales (plenas, no apocopadas) pueden funcionar como modificadores antepuestos o postpuestos al segmento lingüístico al que restringen. En posición prenuclear encontramos numerales cardinales y el identificativo mismo, en tanto que en distribución postnuclear aparecen demostrativos, posesivos e indefinidos:

(24) Estos seis años fueron maravillosos

(25) El mismo Juan me aclaró todo

(26) El niño este me está volviendo loca

(27) Este hijo mío me está volviendo loca

(28) Una mujer cualquiera puede realizar esta labor

\section{Los prototipos pronominales y sus desviaciones}

Como hemos podido observar en los apartados anteriores, en la definición y clasificación de la mayor parte de las clases de palabras, si no en todas, y entre ellas, por supuesto, en el área del pronombre, se debe operar desde un prisma gradual asociado a unidades más o menos prototípicas relacionadas, consecuentemente, con propiedades más o menos prototípicas.

En esta línea de investigación, también se ha podido deducir con relativa claridad y, creemos que contundencia, los parámetros que han servido de punto de referencia. De hecho, y siguiendo un orden decreciente de relevancia estructural, son los siguientes: el parámetro sintáctico-distribucional (presencia o ausencia de determinante precediendo al pronombre), el nivel morfológico (presencia de accidentes gramaticales exclusivos de algunos pronombres como el caso, además de los compartidos por otros subtipos de palabras: el género neutro (accidente que el pronombre comparte con el artículo) y la persona (este accidente gramatical lo comparte con el verbo).

Por su parte, la óptica nocional o semántica no aporta datos pertinentes en tanto son comunes a otros subtipos de palabras.

Apliquemos, pues, estos parámetros a la clase pronominal:

\section{PROTOTIPOS---:------------ $\rightarrow$ DESVIACIONES}

Personales

Demostrativos

Posesivos sin determinante

Indefinidos sin determinante

Interrogativos

Exclamativos
Indefinidos con determinante

Posesivos con determinante

Relativos 
En la esfera de los prototipos pronominales se encuentran seis subtipos, de los cuales dos tan sólo remiten parcialmente al comportamiento más prototípico: los posesivos y los indefinidos sin determinante. El resto de los pronombres no "suelen" ir acompañados de determinante (ni de modificador), se vinculan a una morfología flexiva rica y variada (los pronombres que muestran superior inmovilidad flexiva son los interrogativos y los exclamativos, seguidos muy de cerca por los indefinidos sin determinante) y constituyen, prácticamente todos, componentes deícticos sustitutos (menos los personales yo y tú).

Los indefinidos con determinante se consideran menos desviados en relación con el prototipo ideal que los posesivos con determinante y que los relativos, ya que se tiene en cuenta que aquellos son mucho menos frecuentes, y por tanto, que esta opción construccional está menos fijada, que los posesivos con determinante (aparecen necesariamente en las funciones primarias, exceptuando el atributo o predicativo) y que los relativos.

Estos últimos, como podremos deducir, son las entidades pronominales menos prototípicas. De hecho, el vínculo formal a los prototipos estriba en la ausencia parcial, pero mayoritaria cuantitativamente, del determinante (excluimos las formas el cual y el que, tratadas en apartados anteriores) y la posibilidad de desempeñar funciones sintácticas en el interior de la oración subordinada en la que se materializan. No obstante, su naturaleza nexual (cercana al comportamiento de preposiciones y conjunciones), su inmovilidad formal (tan sólo varía en número el relativo quien(es)) y su perfil deíctico no sustituto en todos los casos, además de su naturaleza átona (exceptuando la forma el cual), nos conducen a esta consideración desviada.

\section{Posible clasificación de las clases de palabras del español}

Precisamente, esta visión gradual fundamentada en diferentes parámetros es la que nos permite desarrollar una caracterización y/o clasificación de las distintas clases de palabras de la lengua española.

En este sentido, pretendemos ofrecer pautas estructurales "relativamente" regulares (nunca "absolutamente", estemos ante un tipo de palabra u otro), otorgando preeminencia a aquellas de raigambre sintáctico-distribucional y formal frente a las de naturaleza nocional $\mathrm{y}$ acentual.

Creemos que tal taxonomía integra, al menos de forma coherente desde el punto de vista en el que nos hemos instalado casi desde el principio de este trabajo, el pronombre en relación con los otros tipos de palabras, en consecuencia, en oposición directa o indirecta a estos.

\subsection{Caracterización formal}

\section{El sustantivo ${ }^{18}$}

18 En el ámbito del sustantivo se suele distinguir, en primera instancia, entre sustantivos comunes (grosso modo, unidades lingüísticas con significado léxico, en tanto que designan clases de objetos o seres) y sustantivos propios (con carácter identificativo, no significado léxico). La inclusión de los sustantivos o nombres propios en la clase sustantivo no está exenta de ciertos problemas (cfr. Bajo Pérez, 2002 y Fernández Leborans, 1999):

(a) El nombre propio no tiene significado léxico.

(b) No admite con igual naturalidad y frecuencia que el sustantivo común la presencia de determinantes y de modificadores, aunque es indudable que existen nombres propios con determinante, posibilidad que se ha 
1.1.1. Mecanismos morfológicos: presencia de género y número inherentes y de morfemas (prefijos y sufijos: pre-historia vs. hombre-cito).

1.1.2. Mecanismos sintáctico-distribucionales: presencia de actualizadores y modificadores (Esas ideas tuyas/fascistas no son buenas).

1.1.3. Mecanismos semánticos: se refieren a un objeto o ser que remite a [+clase].

\subsection{Caracterización nocional}

1.2.1. Sustantivos deícticos o referenciales: asunto, cosa, cuestión...

1.2.2. Sustantivos léxicos: día, amor, niño...

1.3. Caracterización acentual: los sustantivos son siempre tónicos (autonomía sintáctico-semántica).

\subsection{Caracterización formal}

\section{El adjetivo}

2.1.1. Mecanismos morfológicos: género y número no inherentes, además de la presencia del mecanismo de la gradación (expresada de forma sintética o analítica: paupérrimo vs. muy pobre) o de morfemas (prefijos y sufijos: requete-ocupado, ocupad-ísimo).

2.1.2. Mecanismos sintáctico-distribucionales: da lugar a estructuras sintácticas cuyo esquema es: núcleo + modificador y verbo + atributo o predicativo (Los inmigrantes colombianos han llegado a Cádiz, Esa idea es brillante).

2.2. Caracterización nocional: rasgos [+cualidad] o [+clase]. Estas cualidades están asociadas a dos clases de adjetivos que se fundamentan en propiedades de naturaleza formal y sintáctica (adjetivos calificativos $v s$. adjetivos clasificadores o relacionales: guapo, feo, tonto vs. nuclear, americano, agrario).

2.3. Caracterización acentual: son siempre tónicos (autonomía sintáctico-semántica).

\section{El verbo}

\subsection{Caracterización formal}

de incluir: en el discurso repetido y no en la técnica libre del discurso (A Coruña, Las Antillas, Los Alpes, Los Andes, Los Pirineos, Las Canarias, El País vasco...); en los usos peyorativos de los nombres propios (La Maria, El Pepe...); o en usos plurales no peyorativos (Los Luises, Los Juanes, Los Fernández...). Asimismo, los sustantivos propios pueden aparecer acompañados de los identificativos mismo o propio, de aposiciones, o de estructuras explicativas (también denominadas incisos explicativos): E/ mismo/propio Juan me lo dijo; Juan, el hijo de Luis, me llamó por teléfono; Juan, que/quien siempre dice la verdad, ine lo garantizó.

(c) Habría que ver en qué medida el nombre propio tolera, como el común, la presencia de morfemas derivativos no diminutivos y la de morfemas flexivos de número.

Lo que queremos constatar es que la inclusión del nombre propio en la clase sustantiva seguramente está asociada a una decisión convencional para evitar la multiplicación terminológica. Esto no quiere decir que sea una decisión carente de fundamentos lingüísticos, dado que suele ser justificada su naturaleza sustantiva a través de la incorporación del actualizador en el nombre propio, además de que desempeña las funciones sustantivas (esto es, todas), pero sí que es un aspecto no abordado, en muchas oportunidades, en profundidad por parte de los investigadores. De hecho, a cada propiedad individualizadora del nombre propio se le podría oponer otra totalmente distinta. Esto evidencia que el sistema lingüístico se muestra ante el estudioso como un continuum que este ha de sistematizar desde un punto de vista inmanentista, opte por una vía conceptual y/o terminológica o por otra diferente. 
3.1.1. Mecanismos morfológicos: presencia de accidentes gramaticales como el número, la persona, el tiempo, la voz, el modo y el aspecto (los dos primeros concordantes y los cuatro últimos inherentes).

3.1.2. Mecanismos sintáctico-distribucionales: son siempre el núcleo del predicado,

3.2. Caracterización nocional

3.2.1. Verbos deícticos o referenciales: hacer, realizar...

3.2.2. Verbos léxicos: comer, soñar, sollozar, ver...

3.3. Caracterización acentual: son siempre tónicos (autonomía sintáctico-semántica).

\section{El adverbio}

4.1. Caracterización formal

Mecanismos morfológicos: ausencia de categorías gramaticales aunque, en ocasiones, se combinan con morfemas derivativos que significan gradación o naturaleza aumentativa/diminutiva (lejisimos, cerquísima, prontito, lejazos).

4.2. Caracterización sintáctico-distribucional: funcionan como modificador de un adjetivo o de un adverbio en el nivel frasal y como complemento circunstancial en el estrato oracional (Resulta tremendamente complejo, Todo resultó muy bien, Ayer me encontré con tu hermano).

4.3. Caracterización nocional

4.3.1. Adverbios deícticos o referenciales: aquí, ahí, alli, entonces, mañana, hoy, asi...

4.3.2. Adverbios léxicos: animadamente, bien, mal...

4.4. Caracterización acentual: son siempre unidades tónicas (autonomía sintáctico-semántica).

\section{El determinante ${ }^{19}$}

5.1. Caracterización formal

5.1.1. Mecanismos morfológicos: género y número no inherentes.

5.1.2. Mecanismos sintáctico-distribucionales: aparecen siempre antepuestos al elemento al que acompañan desempeñando la función sintáctica determinante (EI / este / su / cualquier hijo nos puede hacer daño). El único determinante nexual es cuyo, elemento que exige la presencia de un antecedente (La madre cuyo hijo suspendió esta asignatura es muy grosera).

5.2. Caracterización nocional: remiten siempre a una deixis no sustitutiva.

5.3. Caracterización acentual: como norma "relativamente" general son elementos átonos (excepto los determinantes demostrativos, los cuantificadores, los interrogativos y los exclamativos).

\section{El pronombre}

\subsection{Caracterización formal}


6.1.1. Mecanismos morfológicos: variables en su comportamiento (vid. supra apdo 2.1.)

6.1.2. Mecanismos sintáctico-distribucionales

6.1.2.1. Pronombres nexuales $v$. pronombres no nexuales (los relativos y los interrogativos indirectos vs. la restante clase pronominal: Dime lo que quieres, Dime qué quieres).

6.1.2.2. Ausencia de actualizadores (o determinantes) y de modificadores, aunque no siempre (el mismo, lo demás, el otro, el primero, yo mismo...).

6.1.2.3. Ausencia de derivación prefijal y, en general, sufijal (mismísimo, poquísimo, muchísimo, tantísimo).

6.2. Caracterización nocional: naturaleza deíctica sustitutiva y no sustitutiva o referencial (endofórica o exofórica).

6.3. Caracterización acentual: se trata de unidades lingüísticas siempre tónicas.

7.1. Caracterización formal

\section{Preposición y conjunción}

Mecanismos morfológicos: invariables.

7.2. Caracterización sintáctico-distribucional: funcionan como nexos con distribución fija.

7.3. Caracterización nocional: significado básicamente gramatical.

7.4. Caracterización acentual: en general, son unidades átonas, pero no siempre ${ }^{20}$ (según, a través de, sin embargo, no obstante, puesto que...).

\section{Referencias bibliográficas}

Alarcos Llorach, E. (1970a): "Los pronombres personales". En Alarcos Llorach, E.: Estudios de Gramática funcional del español. Madrid, Gredos, págs. 200-212.

Alarcos Llorach, E. (1970b): "Los demostrativos en español". En Alarcos Llorach, E.: Estudios de Gramática funcional del español. Madrid, Gredos, págs. 287-306.

Alarcos Llorach, E. (1970c): "El artículo en español". En Alarcos Llorach, E.: Estudios de Gramática funcional del español. Madrid, Gredos, págs. 223-234.

Alarcos Llorach, E. (1994): Gramática de la lengua española. Madrid, Espasa-Calpe.

Alcina, J. y J. M. Blecua (1975): Gramática española. Barcelona, Ariel.

Álvarez, M. Á. (1989): El pronombre. I. Personales, artículo, demostrativos, posesivos. Madrid, Arco/Libros.

Alonso, A. y S. Henríquez Ureña (1971): Gramática castellana, primer curso. Buenos Aires, Losada, $26^{a}$ ed.

Bajo Pérez, E. (2002): La caracterización morfosintáctica del nombre propio. Colección Lingǘstica $n^{\circ}$ 3. A Coruña, Editorial Toxosoutos.

Bloomfield, L. (1933): Language. Nueva York, Holt, Rinehart and Winston. Seguimos la versión esp.: Lenguaje. Lima, Universidad de San Marcos, 1964.

Carbonero Cano, P. (1979): Deixis temporal y espacial en el sistema lingüistico. Sevilla, Publicaciones de la Universidad de Sevilla. 
Eguren, L. J. (1999): "Pronombres y adverbios demostrativos. Las relaciones deícticas". En Bosque, I. y Demonte, V. (dirs.): Gramática descriptiva de la Lengua española, vol. 1 (Sintaxis básica de las clases de palabras). Madrid, Espasa-Calpe, págs. 929-972.

Fernández Leborans, M. J. (1999): "El nombre propio". En Bosque, I. y Demonte, V. (dirs.): Gramática descriptiva de la Lengua española, vol. I (Sintaxis básica de las clases de palabras). Madrid, Espasa-Calpe, págs. 77-128.

Fernández Ramírez, S. (1987): Gramática española. 3.2. El pronombre, volumen preparado por José Polo. Madrid, Arco/Libros.

Fernández Soriano, O. (1993): "Los pronombres átonos en la teoría gramatical. Repaso y balance". En Fernández Soriano, O. (ed.): Los pronombres átonos. Madrid, Taurus Universitaria, págs. 13-62. Fernández Soriano, O. (ed.) (1993): Los pronombres átonos. Madrid, Taurus Universitaria.

Fernández Soriano, O. (1999): "El pronombre personal. Formas y distribuciones. Pronombres átonos y tónicos". En Bosque, I. y Demonte, V. (dirs.): Gramática descriptiva de la Lengua española, vol. 1 (Sintaxis básica de las clases de palabras). Madrid, Espasa-Calpe, págs. 1209-1273.

Fontanella de Weinberg, M. B. (1999): "Sistemas pronominales de tratamiento usados en el mundo hispánico". En Bosque, I. y Demonte, V. (dirs.): Gramática descriptiva de la Lengua española, vol. 1 (Sintaxis básica de las clases de palabras). Madrid, Espasa-Calpe, págs. 1399-1425.

García-Miguel, J. M. (1991): "La duplicación de complemento directo e indirecto como concordancia", Verba, 18, Universidade de Santiago de Compostela, págs. 375-410.

García-Miguel, J. M. (1995a): Transitividad y complementación preposicional en español, Verba, Anexo 40, Universidade de Santiago de Compostela.

García-Miguel, J. M. (1995b): Las relaciones gramaticales entre predicado y participantes, Lalia, 2 (Series Mayor), Universidade de Santiago de Compostela.

García-Miguel, J. M. y V. Vázquez Rozas (1994): "Lingüística de corpus y lingüística descriptiva: el caso de la duplicación de objetos", Boletín de la SPLN, 14, págs. 47-62.

Gili Gaya, S. (1973): Curso superior de sintaxis española. Barcelona, Biblograf, $11^{\text {a }}$ ed.

González Calvo, J. M. (1982): "Consideraciones sobre la palabra como unidad lingüística", RSEL, 12/2, págs. 375-410. También aparece en González Calvo, J. M.: Estudios de morfología española. Cáceres, Universidad de Extremadura, 1988, págs. 11-37.

González Calvo, J. M. (1998): "Sobre partes de la oración: artículo, pronombre, adverbio, interjección". En González Calvo, J. M.: Variaciones en torno a la Gramática española. Cáceres, Universidad de Extremadura, págs. 257-281.

Heger, K. (1966): "La conjugaison objective en français et en espagnol”, Langages, 3, págs. 19-39.

Hjelmslev, L. (1928): Principes de grammaire genérale. Copenhague, Munksgaard. Seguimos la versión esp.: Principios de gramática general. Madrid, Gredos, 1976.

Jaeggli, O. A. (1993): "Tres cuestiones en el estudio de los clíticos: el caso, los sintagmas nominales reduplicados y las extracciones". En Fernández Soriano, O. (ed.): Los pronombres átonos. Madrid, Taurus Universitaria, págs. 139-173.

Lapesa, R. (1975): "Sintaxis histórica del adjetivo calificativo no atributivo", en Homenaje al Instituto de Filologia y Literatura Hispánicas "Dr. Amado Alonso" en su cincuentenario (1923-1973). Buenos Aires.

Lázaro Carreter, F. (1975): "El problema del artículo en español". En Estudios de lingüistica. Barcelona, Crítica, 1980, págs. 27-59.

Lenz, R. (1935): La oración y sus partes. Madrid, Publicaciones de la Revista de Filología Española.

Leonetti, M. (1999): Los determinantes. Madrid, Arco/Libros.

López Palma, H. (1999): La interpretación de los cuantificadores. Aspectos sintácticos y semánticos. Madrid, Visor Libros.

Llorente, A. y J. Mondéjar (1974): "La conjugación objetiva en español", RSEL, 4/1, págs. 1-60.

Marcos Marín, F. (1972): Aproximaciones a la gramática española. Madrid, Cincel. 
Marcos Marín, F. (1978): Estudios sobre el pronombre. Madrid, Gredos.

Marcos Marín, F., F. J. Satorre Grau y M. L. Viejo Sánchez (1998): Gramática española. Madrid, Síntesis.

Marcos Marín, F. A. (1999): "Los numerales". En Bosque, I. y Demonte, V. (dirs.): Gramática descriptiva de la Lengua española, vol. 1 (Sintaxis básica de las clases de palabras). Madrid, Espasa-Calpe, págs. 1189-1208.

Picallo M. C. y G. Rigau (1999): "El posesivo y las relaciones posesivas". En Bosque, I. y Demonte, V. (dirs.): Gramática descriptiva de la Lengua española, vol. 1 (Sintaxis básica de las clases de palabras). Madrid, Espasa-Calpe, págs. 973-1023.

Porto Dapena, J. Á. (1982): "Los posesivos personales en español: intento de descripción funcional", Dicenda, Cuadernos de Filología Hispánica, 1, págs. 55-108.

Quilis, A. (1997): Principios de fonología y fonética española. Madrid, Arco/Libros.

R.A.E. (1973): Esbozo de una mueva gramática de la lengua española. Madrid, Espasa-Calpe.

Rojo, G. (1983): Aspectos básicos de sintaxis funcional. Málaga, Ágora.

Rojo, G. y T. Jiménez Juliá (1989): Fundamentos básicos de sintaxis funcional, Lalia, 2, Universidade de Santiago de Compostela.

Saussure, R. de (1916): Cours de linguistique genérale (ed. Por Ch. Bally y A. Sechehaye, con la colaboración de A. Riedlinger). Seguimos la versión esp.: Curso de lingüistica general. Madrid, Alianza, 1983.

Seco, M. (1989): Gramática esencial del español. Introducción al estudio de la lengua, $2^{\mathrm{a}}$ edición, revisada y aumentada. Madrid, Espasa-Calpe, 1991.

Seco, R. (1930): Manual de gramática española. Madrid. Seguimos la edición revisada por M. Seco. Madrid, Aguilar, 1988".

Suñer, M. (1993): "El papel de la concordancia en las construcciones de reduplicación de clíticos". En Fernández Soriano, O. (ed.): Los pronombres átonos. Madrid, Taurus Universitaria, págs. 174204. 